\title{
Building Emotional Authenticity between Humans and Robots
}

\author{
Julienne Aleta Greer \\ University of Texas at Arlington, 701 S. Nedderman Drive - Arlington, Texas \\ jgreer@uta.edu
}

\section{Introduction}

On June $5^{\text {th }} 2014$, a robot named Pepper, hailed as emotionally responsive and meant solely to emotionally interact with human beings, was unveiled in Japan. "Our aim is to develop affectionate robots that can make people smile" [12] stated Softbank CEO Masayoshi Son. But what did Masayoshi mean the robot would "make people smile?" Did he mean the robots behavior might elicit a smile from a human? If so, some people smile when they are angry in order to make themselves less aggressive in a tense situation. Certainly, he did not mean he developed a robot to make people angry! So we may assume Masayoshi meant human interaction with Pepper would make people "happy". However, by what methodology do we determine the robot created happiness in us? The viewpoint of this essay is that the humanities and specifically the performing arts are in an excellent position to develop a model of behavior between humans and robots in order to present a clear, authentic emotional relationship between them. Meaning, the social intelligence of a robot interacting with a human is akin to the dramatic relationship between human beings while performing for an audience.

The stage is the social arena and the performance styles are the tools with which to sculpt a meaningful performance. We must begin to understand how we perform for each other all the time as we are essentially building robots to perform for us. This is not an entirely new concept. Erving Goffman, notable sociologist used the metaphor of the stage to dramatize his views of how human social interaction is a series of performances that we tweak and mold instantaneously both inter- and intra-personally.

"Within the walls of a social establishment we find a team of performers who cooperate to present to an audience a given definition of the situation. This will include the conception of own team and of audience and assumptions concerning the ethos that is to be maintained by rules of politeness and decorum" [5].

Goffman discusses the presentation of self through a social situation in which we often try to cooperate with our fellow social actors. "Typically, but not always, agreement is stressed and opposition is underplayed"[5], yet the expression of emotion in human beings does not always follow such agreeable rules. Goffman 
wrote specifically how the individual compartmentalizes his responses into a "front" of the house - the actor and performer- and the "back" of the house -the performers true identity [5].

This essay seeks to present a system to express deeper emotional authenticity through the utilization of performance behavior, gesture, shape, and relationship. This is accomplished through the implementation of traditional performance techniques re-contextualized from a human/human stage model to a human/robot social intelligence model.

\section{Social Intelligence, Attention and Authenticity}

When analyzing social intelligence between robots and humans, we must be cognizant of the complexity and specificity of emotional connections human beings share with each other in the multitude of everyday moments of interaction. Why is the artist involved in this decision? Performers study an art form nearly 3,000 years old that demands a level of authenticity and skill from a collaborative team including actor, director, and playwright. There are few art forms or disciplines as adept as that of the theatre artist to convey how to create, hold, build, and challenge attention from a group of people -the audience- from whom no previous relationship was originally held. And yet, social intelligence, by definition, strives to do just that. Drama and the performing arts, specifically well-known performance techniques, can be used to understand, deepen, and clarify emotions, as well as, focus attention in a social relationship not only through human connection, but by expanding performance techniques to relate to human beings interacting with robots and vice versa.

Many visionaries have used the medium of drama and performance to express their artistic ideas. Constantin Stanislavski (1863-1938) emphasized natural, (re)created, emotional expression in response to the arguably more superficial theatre of the time. "The approach we have chosen -the art of living a partrebels with all the strength it can muster against those other current 'principles' of acting. We assert the contrary principle that the main factor in any form of creativeness is the life of a human spirit, that of the actor and his part, their joint feelings and subconscious creation" [9]. Theatre director/actor Stanislavski is widely considered the 'father' of modern theatre and his Stanislavski system was the framework for "the method" which was refined and popularized by Lee Strasberg in the U.S.

When creating successful drama in the theatre arts we speak about specifics of a character through their behavior, their gesture, their shape and the interaction of those attributes functioning through the very specific relationship implied between the characters. In order to make sense of behavior, gesture, shape, and relationship, the artist must determine the given circumstances of the play.

These technical terms are defined as follows:

Given circumstances: the givens of the moment in a play. Essentially, where a character finds themselves (physically and emotionally) at that moment 
in their world and how they respond to people and events and unfolding around them because of those givens.

Behavior: How a character behaves physically and emotionally in order to approach the given circumstances of the specific moment. For example, a character may get down on bended knee to request a proposal of marriage while another drags their partner to the nearest justice of the peace.

Gesture: The movements a character uses within their characters behavior and for what specific effect. For example, take a simple gesture of holding or shaking hands. What variety can be expressed in this simple gestures and what is the meaning in the choice to serve the relationship?

Relationship: What are the parameters of the person with who we share the stage or social arena? For example, are they a peer or subordinate? We speak and act differently to the police officer that has stopped us for speeding than we do to the teenager that has come home past their curfew.

Shape: What is the overall tone of the character and genre the play is trying to express? Can we describe it as comedy, drama, dramedy?

In regards to all the defined terms above, it is assumed that a deepening in the understanding of what the given circumstances are at any one moment culminates in a heighted state of social intelligence. The ability to be cognizant of our social attention skills can be trained; however, is not necessarily training for an artist only. It can be training for an engineer or a roboticist. It is training to explore the nuances of how attention is manifested in social intelligence through the application of performance. One type of attention necessary to understand the given circumstances of social interaction would be the exploration of sensory data. An awareness of what we see, hear, smell, feel kinesthetically both inside our bodies and the tactile experiences on the surface of our bodies, as well as taste. An artist develops an ability to create a relaxation in their body and thereby concentrate the stream of sensory impulses occurring in order to focus, to prioritize, or to give attention to the given circumstances the sensory data refers to. At the moment the sensory data is received, the will of the artist engages. The will is what determines the course of action given the stream of sensory data. It is not enough to simply feel, the will guides the artist in their dramatic objectives and choices. In a social intelligence arena with human robot interaction, the will is the determination that guides attention. In a performance, attention is greatly affected by sensory data culled from the individuals memory, which then affects the artist emotionally.

Yet, the training of sensory impulses and will are not meant to create actors out of an audience of lay people, they are meant to specify and analyze human behavior -which we are all familiar with-from the performative point of view of the artist and now applied to human-robot interaction. The social intelligence of a character in the given circumstances of the current scene, the inter-relating with other characters or the audience, and ultimately how or why the character behaves, is the research now transcribed to the relationship between humans and robots. The very best conclusion for human-robot interaction would contain not only an authentic sense of how humans behave between themselves in 
relationship-based dramatic circumstances -theatre arts- but also how a human may interpret and thereby behave with a robot with whom they may begin to have very human-like emotional relationships with.

\section{The Building Blocks of Authenticity}

\subsection{Toward Performative Arts}

If we are to look toward the artist for answers in how humans respond to humans and ultimately how humans may respond with robots, there is a need to research the many technicians, directors, and artistic visionaries, who created performance styles for the performing artist. These performance styles present an exploration of behavior, gesture, shape and relationship as it relates to how human beings interact and how robots must behave if human beings are to authentically interact with them. Research points toward the efficacy of longstanding performance techniques or styles, styles that has survived through not only decades but centuries of performance. The preference to present two different, yet mutually compatible, framing mechanisms to illustrate how human beings may interact with our robot companions, is a helpful aspect.

The first technique presented is Vsevolod Meyerhold's biomechanics [1]. Meyerhold's biomechanics is a performance technique that stresses external physicalization, gestures, behavior, and avant-garde themes and movement to create emotion and authentic characterization in the performer. It is representational, abstract, and features a theatrical expression known as the grotesque ${ }^{1}$. Biomechanics is an external performance technique created, developed, and best exemplified by Meyerhold with his work in Russia from the 1890s to the present. Life of Man by Leonid Andreev with its exemplary lighting design is one example of Meyerhold's innovative work from this time [1].

Although contemporaries, Meyerhold's techniques were quite different from the second presented performance technique: Lee Strasberg's method [10]. Originally developed from Constantin Stanislavski's techniques, Strasberg's method technique stresses thoughts, psychological motivations and desires, personal memories, and naturalistic behavior and movement to create emotive characterizations in the performer. Internal performance technique was created, developed, and best exemplified by Lee Strasberg and his work to create the method system in the United States from the 1920s to the present. Most notable of Lee Strasberg's work was the co-creation of the legendary yet short-lived, The Group Theatre, and specifically the production directed by Strasberg of Golden Boy by Clifford Odets produced to notable acclaim both on Broadway and in London [3].

This research utilizes aspects of both contrasting performance techniques to fully develop intense and effective emotive bond between humans, and now as technology is creating emotional robots, between humans and robots.

\footnotetext{
${ }^{1}$ The grotesque theatre as defined by Bert Cardullo and Robert Knopf is simply "the resolving of tragic situations into comedy or the reverse" [2]
} 
The function of a performance technique is to deepen the authenticity of the performer so the relationship between the player and the audience is more immersive and ultimately more satisfying. We go to the theatre to feel something -a human connection, an understanding of why this human being, in these circumstances, made these choices. That understanding is similarly translatable to a relationship between a robot and a human, in fact it is wanted and desired. Attention for social intelligence will be most effective if it stresses immersive emotional and relational bonds. As robots move into the social arena of companions to humans, it is imperative to understand and create relationships on a sincere and accessible performance level.

The proposed performative methods might be an innovative and interesting way to elucidate a unique insight to the authentic emotional responses required when working with actors, digital characters (videogame characters), animators, and now, engineers and roboticists.

\subsection{When Emotions are more than Right or Wrong}

When speaking of emotion, a significant caveat is that although there may be many different ways to express emotion, there are very few emotions to express. Some psychological studies theorized a model of emotions based on only a limited number of primary emotions. Paul Ekman theorizes six basic emotions [4] while a recent study conducted at Glasgow University now proposes only four [7]. Yet, through this limited landscape the artist seems fluent in a nearly infinite variety of expression across a landscape of social, cultural, and geographic framing structures. One method for accessing emotional authenticity in performance is to eliminate a judgment of right or wrong in defining the emotion.

There is a common tendency to assign emotion as right or wrong. Anger may be considered a bad emotion while courage is good. However, research consistently highlights that authentic, expressive human emotion relies very little on the right or the normal relationship. This tendency has been observed in sociological studies made by MIT professor, Sherry Turkle. Turkle introduced a study she conducted with children and a robot named Cog [11]. In her analysis, Turkle notices the children enjoying their interaction with Cog. The children played with the robot and seemed to nurture it and care for it. "They treated it as a creature with needs, interests, and a sense of humor" [11]. The children seemed quite bonded to the robot and accepted Cog as a playmate as they would a human child or peer with all the usual emotional responses that human beings reserve for their human counterparts. The children's behavior implied that Cog was not less of a playmate because Cog was not human. This summation was not completely unexpected by Turkle who has cited Joseph Weizenbaum's work regarding the Eliza Effect and its strong emotional influence on its participants [11]. However, Turkle also planned a meeting with Cog where each child was systematically shown Cog's inner mechanisms and working parts. Cog was exposed as plastic, metal, and digital instructions. The childrens relationship with Cog was not normal in any socially conforming version of a typical relationship, yet none of this mattered. The children again quickly related to Cog in the same nurturing, 
relational manner as before the nuts and bolts explanation. Nurturance is the relationship in this given circumstances that drove the children's emotions to care for Cog. The children cared for Cog the same way they seem to care for and feel for each other. Even though, as Turkle laments, "To have a relationship, the issue is not only what the human feels but what the robot feels" [11]. Turkle summarized the study stating nurturance should be known as the "killer app" [11], creating a bond between humans and non-organic objects that is incredibly strong. Therefore, although cultural norms of right, wrong, or normal may be recognized, they are secondary to the authenticity and creation of emotion, and the relationship that may form because of that creation of emotion.

\subsection{Human-Robot Mutual Need: an Analogy with Drama}

One way to deepen the relationship between humans and robots is to note that human relationships are often based on mutual need. Drama is a series of ever unfolding conflicts continually testing the bounds of which character's need is currently being fulfilled. Humans respond favorably to the act that helps another while it also fills a need for them. This inter-relationship is being explored in a human-robot relationship. For example, Okada Michio developed a robot that does not pick up trash, but rather finds it and requests a human's help to accomplish its task [6]. In this instance, when the robot finds a piece of litter, it does not function autonomously, but rather indicates the location of the litter and with an angled bow, requests the help of a human to pick it up. The implication is clear; let's work together and see what we can accomplish. Okada believes this relationship creates a desire to nurture the robot echoing Sherry Turkle's study.

\subsection{The Perfection of Imperfections}

Another method of building a relationship may be in the creation of a robot whose characteristics are imperfect. Just an in human beings, some of the most unique and charming human characteristics are those that are seemingly imperfect -a gap tooth, a cowlick in the hair- an imperfect robot might be one that stutters occasionally, or develops a limp after moving for an extended period of time. As illustrated by the uncanny valley ${ }^{2}$ research, human engagement is not in what is perfect, but rather in the abstract or the imperfect. Imperfection in all its unique qualities is endearing to humans. It would follow that we may like our robots to be more imperfect in order to bond emotionally with them.

\footnotetext{
${ }^{2}$ The uncanny valley was a term originally coined by Masahiro Mori in 1970 to describe the eerie and unsettling response of people when confronted with an android that is not quite human. The uncanny arises when one is confronted with something that transgresses the boundaries of our conceptions of normal, and thus seems to be one of the key responses invoked in confrontations with the border between humans and machines [8]
} 


\section{Conclusions}

When developing robots that will help us in our day-to-day lives should we be looking at the mutual need humans and robots may begin to feel for each other? How will those relationships be expressed? How can we develop robots that spur our desire to connect with them in order to fulfill the individual's wishes and needs? Will a robot ever have a need for a human's emotional attention? These are all relevant questions for future research.

Given the proposition that the analysis of the human condition through performance is helpful, and even essential, in the development of social, attentive, emotional, and empathetic human beings, are performance techniques then essential to analysing the behavior and relationship between humans and robots in the arena of social intelligence?

Performance, connection, and authenticity are the gold standard that should be hoped for in the creation of the relationship between humans and robots. We can attain these goals through the specific application of understanding human behavior, gesture, shape and relationships. We must be specific in programming robots to respond to, and to eventually to learn from, the human relationships they will be a part of. Social intelligence and the attention to create, improve, and expand the understanding between humans and robots can be positively impacted by the research of performance styles and techniques, specifically internalized method work, and representational biomechanics.

\section{References}

1. Braun, E.: Meyerhold: a revolution in theatre. University of Iowa Press (1995)

2. Cardullo, B., Knopf, R.: Theater of the Avant-Garde, 1890-1950: a critical anthology. Yale University Press (2001)

3. Clurman, H.: The fervent years: The story of the group theatre and the thirties. Hill and Wang (1957)

4. Ekman, P.: Emotions revealed: Recognizing faces and feelings to improve communication and emotional life. Times Books (2003)

5. Goffman, E.: The presentation of self in everyday life (1959)

6. Hayashi, A.: The robot that won't help you (2012), http://www.nippon.com/en/views/b00902/

7. Jack, R.E., Garrod, O.G., Schyns, P.G.: Dynamic facial expressions of emotion transmit an evolving hierarchy of signals over time. Current Biology 24(2), 187$192(2014)$

8. Mori, M., MacDorman, K.F., Kageki, N.: The uncanny valley. Robotics \& Automation Magazine, IEEE 19(2), 98-100 (2012)

9. Stanislavski, C.: Building a character. A\&C Black (2013)

10. Strasberg, L., Morphos, E.: A dream of passion: The development of the method. New American Library (1987)

11. Turkle, S.: Authenticity in the age of digital companions. Interaction Studies 8(3), 501-517 (2007)

12. Yamamoto, A.: Softbank's pepper robot makes emotional debut in japan (2014), http://www.nbcnews.com/tech/innovation/softbanks-pepper-robotmakes-emotional-debut-japan-n123856 